\title{
Survival of Elderly Patients on Maintenance Hemodialysis: A 6 Years' Experience from a Resource-Limited Country
}

\author{
${ }^{1}$ Faculty of Medicine and Biomedical Sciences of Yaounde and General Hospital of Douala, Cameroon \\ ${ }^{2}$ Faculty of Medicine and Biomedical Sciences of Yaounde and Teaching Hospital af Yaounde, Cameroon \\ ${ }^{3}$ Faculty of Medicine and Biomedical Sciences of Yaounde, Cameroon \\ ${ }^{4}$ Faculty of Medicine and Pharmaceutic Science of Douala and General Hospital of Douala, Cameroon \\ ${ }^{5}$ Faculty of Health Sciences of Buea, Cameroon \\ ${ }^{6}$ Faculty of Medicine and Biomedical Sciences of Yaounde and General Hospital of Yaounde, Cameroon \\ ${ }^{7}$ Teaching Hospital of Yaounde, Cameroon \\ ${ }^{8}$ Faculty of Medicine and Biomedical Sciences of Yaounde and General Hospital Of Yaounde, Cameroon
}

Danielle FMEH ${ }^{1 *}$, Francois $\mathrm{KF}^{2}$, Diana $\mathrm{TTH}^{3}$, Patrice $\mathrm{HM}^{4}$, George TD ${ }^{5}$, Mahamat $\mathbf{M}^{6}$, Emmanuel $\mathrm{N}^{7}$ and $\mathrm{Gloria}^{8}$

\begin{abstract}
Background: With the improvement of life expectancy in developing countries, there is a growing population of elderly admitted on maintenance hemodialysis. This study assessed the survival among incident elderly patients on maintenance hemodialysis in Cameroon.

Patients and method: We carried out a retrospective cohort study of 6.3 years in the main hemodialysis units of Cameroon. All incident chronic hemodialysis patients of at least 65 years of age at dialysis initiation were included. Participants were followed for a minimum of 4 months up until death or abandon of dialysis. Their baseline characteristics and survival outcome were assessed.

Results: A total of 107 patients were included in this study, representing a cumulative incidence of hemodialysis among elderly patients of $10.9 \%$ during the study period. The median age at dialysis initiation was 68 years [IQR 66-72]. The median modified Charlson Comorbidity Index $(\mathrm{mCCl})$ was 2 [IQR 2-5], and $35(33 \%)$ patients had a comorbidity index greater than 3. Emergency dialysis at initiation was noted in $71(69 \%)$ participants. Twenty four $(22.5 \%)$ patients were hospitalized, mainly because of sepsis. The median survival time was 19.5 months [IQR 42-6]. Survival rates at 1 year and 2 year were $65.4 \%$ and $41.5 \%$, respectively. The lowest survival time (4 months) was observed in the very elderly (> 80 years) with high comorbidity index. Patients with a history of hospitalization and those with emergency dialysis initiation also had low survival rates.

Conclusion: In our setting, one out of ten incident hemodialysis patients is an elderly. Nearly two-thirds of elderly are still alive one year after hemodialysis initiation. Comorbidity, emergency dialysis initiation and hospitalization are the main factors associated with mortality.
\end{abstract}

Keywords: Elderly; Hemodialysis; Survival; Comorbidity; Emergency dialysis; Hospitalization

\section{Introduction}

Chronic kidney disease (CKD) is one of the major health concerns of the $21^{\text {st }}$ century with an estimated worldwide prevalence of $13.4 \%$ [1]. In the 2015 Global Burden of Disease Study, kidney disease was the 12th most common cause of death, accounting for 1.1 million deaths worldwide [2]. Overall, CKD mortality has increased by $31.7 \%$ over the last 10 years, making it one of the fastest rising major causes of death [2]. With the higher life expectancy due to socioeconomic development, increased prosperity and improvement in medical services, the number of elderly patients with CKD has increased. This rise is also due to the high prevalence of traditional risk factors of CKD such as diabetes and hypertension in older adults. So, the number of older patients reaching end stage renal disease (ESRD) is rising. In the United States of America (USA), the prevalence of ESRD continues to increase, with the fastest growing rate among patients above 65 years. From 2000 to 2016 , the prevalence of ESRD in older patients ( $\geq 65$ years) increased by $50 \%$; and since 2000 , older patients have the highest incidence rate of ESRD [3]. In Europe, older patients accounted for $42 \%$ of the European ESRD patients treated in 2012 [4]. However, limited data on the survival benefits of elderly adults initiating dialysis have been reported. Recent studies highlighted the uncertain survival benefit of renal replacement therapy in elderly, particularly among those with extensive comorbidities [5-8]. Besides the high burden of preexisting comorbidities, dialysis treatment itself may be associated with a further deterioration in functional status in this population. In Austria, ReindlSchwaighofe and al, observed that elderly patients with ERSD benefited from initiation of hemodialysis, but this survival benefit did not persist beyond the first two months compared to survivors on conservative treatment [8].

In Sub-Saharan Africa, more than 500,000 individuals develop ESRD every year and less than $2 \%$ of them have access to renal replacement therapy [9]. In Cameroon, CKD mainly affect young adults but recent studies have shown that elderly may account for $20 \%$ of CKD population [10]; meaning that older patient may reached ESRD and need dialysis. Thus, elderly could represent a significant proportion of the dialysis population. In resourced-limited countries such as Cameroon, although it is partially founded by The State, access to dialysis is still limited, with mortality rates of more than $50 \%$ and

*Corresponding author: Danielle FMEH, Faculty of Medicine and Biomedical Sciences of Yaoundé and General Hospital of Douala, Cameroon, Tel: +237662962868; E-mail: mendjouf@yahoo.fr

Received: April 29, 2019; Accepted: June 10, 2019; Published: June 15, 2018

Citation: Danielle FMEH, Francois KF, Diana TTH, Patrice HM, George TD, et al. (2019) Survival of Elderly Patients on Maintenance Hemodialysis: A 6 Years' Experience from a Resource-Limited Country. J Nephrol Ther 9: 331.

Copyright: ( 2018 Danielle FMEH, et al. This is an open-access article distributed under the terms of the Creative Commons Attribution License, which permits unrestricted use, distribution, and reproduction in any medium, provided the original author and source are credited. 
Citation: Danielle FMEH, Francois KF, Diana TTH, Patrice HM, George TD, et al. (2019) Survival of Elderly Patients on Maintenance Hemodialysis: A 6 Years' Experience from a Resource-Limited Country. J Nephrol Ther 9: 331.

Page 2 of 8

overall means survival of less than 12 months [11]. The picture could be worse among elderly patients.

\section{Objectives}

In this study, we evaluated the survival rate of incident elderly patients ( $>65$ years) admitted in the three main hemodialysis centers of Cameroon.

\section{Methodology}

\section{Study design}

This was a multicenter retrospective cohort study conducted from the January $1^{\text {st }} 2012$ to April $30^{\text {th }} 2018$. Patients were recruited in 3 hemodialysis centers:

- The Douala General Hospital Hemodialysis Center (DGHC) is the oldest and largest center of the country. It was opened in 1991 and it is located in the economic capital. It has a capacity of 216 patients and it is held by 2 nephrologists. It is the only nephrology reference center serving the littoral region with an estimated population of around 3.2 million.

- The Yaoundé General Hospital Center (YGHC) is the second center of hemodialysis to open. It was open in 2002 and it has a capacity of 153 patients. It is held by 3 nephrologists.

- The Yaoundé Teaching Hospital Center (YTHC) is the third center of the country. It was open in 2012 with a total capacity of 90 patients and it is held by 2 nephrologists.

YGHC and YTHC are both located in the political capital of the country and are the only nephrology centers of the Center region, deserving a population of more than 3.1 million.

Clinical records of incident ESRD patients aged of at least 65 years and admitted in any of the above health facilities during the study period were retrospectively reviewed. Records with incomplete data were excluded. Participants were followed for a minimum of 4 months up until death, abandon of dialysis or kidney transplantation until the end of the study on April $30^{\text {th }}$ 2018. Their baseline characteristics and survival outcome were studied. The modified Charlson Comorbidity index (mCCI) was used to evaluate comorbidity [12]. Patients with $\mathrm{mCCI}>3$ were considered patients with high comorbidity Index.
The study was approved by the University of Yaoundé I Ethical Committee.

Data Collection: Baseline characteristics were recorded in the medical record and completed during an interview if the patient was still alive. The following data was noted:

- Demographic and socio-economic data: age, sex, marital status, profession and residency

- Clinical data: comorbidities by mCCI, etiology of ESRD, predialysis care

- Dialysis initiation data: vascular access, indication of dialysis, programmed or emergency dialysis

- Laboratory parameters: serum creatinine, eGFR, Calcium, potassium and hemoglobin level

The following outcome measures were assessed:

- Survival was defined as patient survival from the date of first dialysis to either death, abandon of dialysis, kidney transplant or end of the study.

- Patient lost to follow up was determined when no information was available concerning death or survival. Contact through phone call was attempted and the status was confirmed if no information on outcome could be obtain.

Statistical analysis: All statistical analysis was performed using the Statistical Package for the Social Science (SPSS), version 23.0. Basic descriptive statistics were computed for the demographic data. Survival outcomes were measured by Kaplan-Meier survival analysis. Chisquare tests and Fisher exact tests were used for the categorical variables and $\mathrm{t}$-tests and Mann-Whitney $\mathrm{U}$ tests for continuous variables as appropriate. Cox proportional hazards models [setting confidence interval (CI) for $\operatorname{Exp}(\mathrm{B})$ at 95\%] were used for predicting factors of mortality. The results were expressed as percentage (\%) or number (n) for categorical variables, and as means \pm standard deviation or median for continuous variables.

Results: From January $1^{\text {st }} 2012$ to December $31^{\text {st }} 2017,1219$ incident patients were registered in the three centers. Among them, 133 were aged of 65 years or above with a cumulative incidence rate of $10.9 \%$ (Figure 1). Twenty six patients were excluded because of incomplete data and a total of 107 patients were included in the analysis.

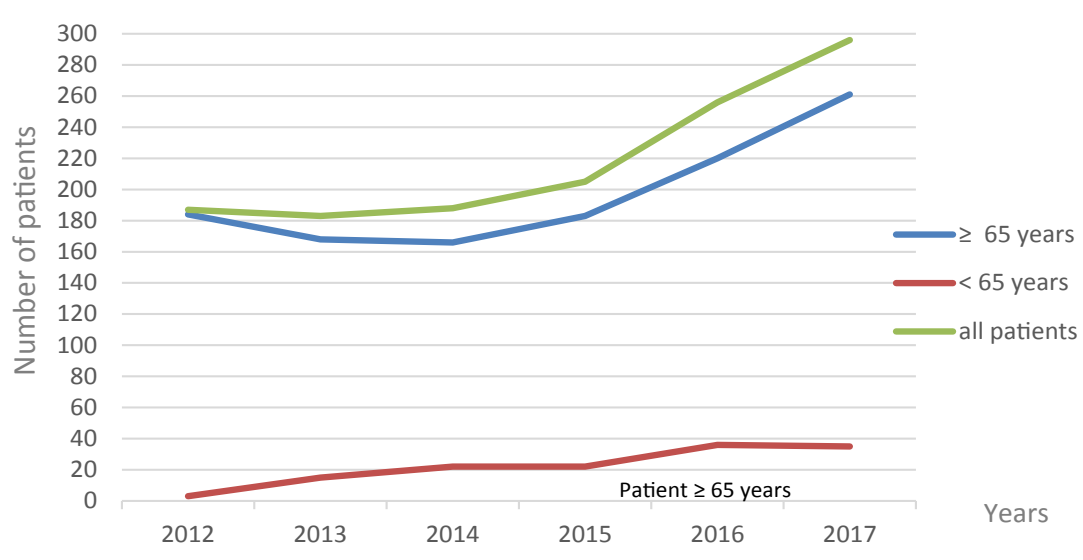

Figure 1: Incidence of end stage renal disease. 
Citation: Danielle FMEH, Francois KF, Diana TTH, Patrice HM, George TD, et al. (2019) Survival of Elderly Patients on Maintenance Hemodialysis: A 6 Years' Experience from a Resource-Limited Country. J Nephrol Ther 9: 331.

Page 3 of 8

\section{Baseline Characteristics}

The median age of the included patients was 68 years (IQR 6572 ) and was comparable between male and female (male $=68$ years, female $=67$ years, $\mathrm{p}=0.14$ ). Most of the patients were married and a third of them were still professionally active. Hypertension $(90.7 \%)$ and diabetes $(72 \%)$ were the two main comorbidities. High comorbidity index was found in $24.3 \%$ of the patients $(n=26)$. Only $54.2 \%$ of the patients had pre-dialysis nephrology care with a median follow up time of 8 months. Hypertension, diabetes and chronic tubulo-interstitial nephritis were the main etiologies of ESRD (Table 1).

Digestive uremic signs and uremic encephalopathy were the most common indications of dialysis initiation. Most of the patients (74\%) started dialysis on a temporary catheter and $23.5 \%(n=25)$ had a hemoglobin level $<7 \mathrm{~g} / \mathrm{dl}$ (Table 2).

\section{Hospitalization and Mortality}

Twenty four patients were hospitalized during the study with 19 patients been hospitalized once and 5 patients twice. Hospitalization

\begin{tabular}{|c|c|c|}
\hline & Effective (n=107) & Percentage (\%) \\
\hline \multicolumn{3}{|l|}{ Socio-demographic data } \\
\hline Male & 73 & 68 \\
\hline $\mathrm{Age}^{*}$ & 68 & {$[65-87]$} \\
\hline$>80$ years & 6 & 5.8 \\
\hline \multicolumn{3}{|l|}{ Marital status } \\
\hline Married & 79 & 73.5 \\
\hline Widow & 20 & 19 \\
\hline Single & 8 & 7.5 \\
\hline \multicolumn{3}{|l|}{ Professional activity } \\
\hline Still working & 36 & 33.6 \\
\hline Illiterate & 9 & 8 \\
\hline \multicolumn{3}{|l|}{ Comorbidities } \\
\hline Hypertension & 97 & 90.7 \\
\hline Diabetes & 77 & 72 \\
\hline HIV & 4 & 3.7 \\
\hline Cerebral vascular accident & 11 & 10.3 \\
\hline Cardiac failure & 31 & 29 \\
\hline Cancer & 11 & 10.3 \\
\hline malnutrition & 5 & 4.6 \\
\hline $\mathrm{mCCl}^{*}$ & 2 & {$[0-10]$} \\
\hline $\mathrm{mCCl} \geq 3$ & 35 & 33 \\
\hline \multicolumn{3}{|l|}{ Pre-dialysis nephrology care } \\
\hline Number of patient & 58 & 54.2 \\
\hline Duration $^{*}$ (months) & 8 & {$[1-65]$} \\
\hline$>12$ months & 27 & 25.2 \\
\hline \multicolumn{3}{|l|}{ CKD stage (first consultation) } \\
\hline 5 & 35 & 60.3 \\
\hline 4 & 12 & 20.7 \\
\hline 3 & 8 & 13.8 \\
\hline 2 & 3 & 5.2 \\
\hline Creation of a Fistula & 24 & 41.4 \\
\hline \multicolumn{3}{|l|}{ Etiology of ESRD } \\
\hline Hypertension & 42 & 39.3 \\
\hline Diabetes & 30 & 28 \\
\hline Chronic tubulo-interstitial nephritis & 18 & 17 \\
\hline Chronic glomerulopathy & 12 & 11.1 \\
\hline Unknown & 5 & 4.6 \\
\hline
\end{tabular}

Table 1: Baseline characteristics of patients.

\begin{tabular}{|c|c|c|}
\hline & Effective $(n=107)$ & Percentage (\%) \\
\hline \multicolumn{3}{|l|}{ Dialysis indication } \\
\hline Digestive uremic signs & 54 & 50.5 \\
\hline Uremic encephalopathy & 52 & 48.6 \\
\hline Acute pulmonary edema & 42 & 39.25 \\
\hline Refractory hyperkaliemia & 18 & 17 \\
\hline Others & 16 & 15 \\
\hline Emergency dialysis initiation & 71 & 69 \\
\hline \multicolumn{3}{|l|}{ Vascular access } \\
\hline Arterio-venous fistula & 24 & 22.3 \\
\hline Permanent catheter & 4 & 3.7 \\
\hline Temporary catheter & 79 & 74 \\
\hline Infection at dialysis initiation & 36 & 33.7 \\
\hline \multicolumn{3}{|l|}{ Laboratory parameters* } \\
\hline eGFR $\left(\mathrm{ml} / \mathrm{min} / 1.73 \mathrm{~m}^{2}\right)$ & $3.5(1.2-5)$ & {$[0-12]$} \\
\hline Hemoglobin (g/dl) & $8.15(7.2-9.5)$ & {$[3.3-12.7]$} \\
\hline Calcium (mg/l) & $82.8(70.25-93.13)$ & [38-136] \\
\hline Potassium (mmol/l) & $5.2(4.4-6.4)$ & {$[2.7-8.8]$} \\
\hline
\end{tabular}

Table 2: Clinical and biological data at dialysis initiation.

\begin{tabular}{|c|c|c|}
\hline \multicolumn{2}{|c|}{ Effective } & Percentage (\%) \\
\hline Causes of death (n=63) & 9 & 14.3 \\
\hline Dialysis redrawn & 7 & 11.1 \\
\hline Infection & 2 & 3.1 \\
\hline Digestive hemorrhage & 1 & 1.5 \\
\hline Cerebral vascular accident & 44 & 70 \\
\hline Unknown & 11 & \\
\hline Hospitalization (n=24) & 7 & 45.8 \\
\hline Catheter infection & 2 & 29 \\
\hline Pneumonia & 1 & 8,4 \\
\hline Digestive hemorrhage & 3 & 4.2 \\
\hline Endocarditis & & 12.6 \\
\hline Others & & \\
\hline
\end{tabular}

Table 3: Death and hospitalization.

was mainly due to sepsis. A total of 63 (59\%) deaths were registered. Most of them occurred at home ( $>50 \%)$. Cause of death was available only for 19 patients (Table 3 ).

\section{Survival}

At the end of the study, 38 (35.5\%) patients were still alive and 6 patients were lost of follow up. The median survival time was 19 months with range from 0.38 to 65 months. Survival at 3 months was $83.5 \%$, at 6 months $73.3 \%$, at 12 months $65.4 \%$ and at 24 months $41.5 \%$ (Figure 2).

Survival time was comparable in the three hemodialysis centers (DGHC $=20$ months vs. YTHC $=19$ months vs. YGHC $=18$ months, $\mathrm{p}=0.53$ ). It was also similar among both sex (male $=19$ months vs. female 14 months, $\mathrm{p}=0.51)$. Survival was lower in very elderly $(>80$ years) compared to other age groups (median survival $65-74$ years $=19$ months, $75-79$ years $=13$ months; $\geq 80$ years $=11$ months, $\mathrm{p}=0.4$ ) but the difference was not statistically significant (Figure 2).

Patients with a high comorbidity index had a lower survival time with an overall survival of 13 months compared to 22 months in patients with lower $\mathrm{mCCI}(\mathrm{p}=0.04)$. The difference between the 2 groups were more important after 6 months (60\% Vs. $72 \%)$. At 24 months, only $25 \%$ of the high comorbidity group survived compared to $45 \%$ in the lower comorbidity group. The lowest survival was found in very elderly with high comorbidity index (median survival=4 months) compared 


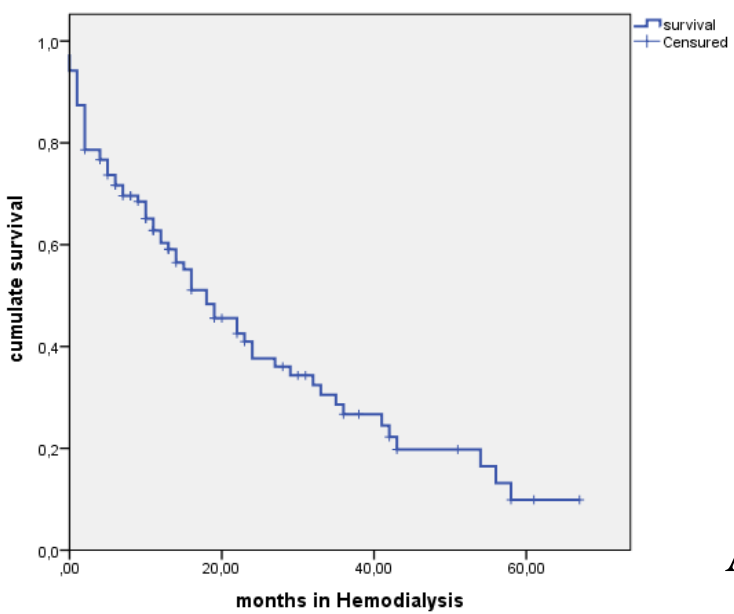

A

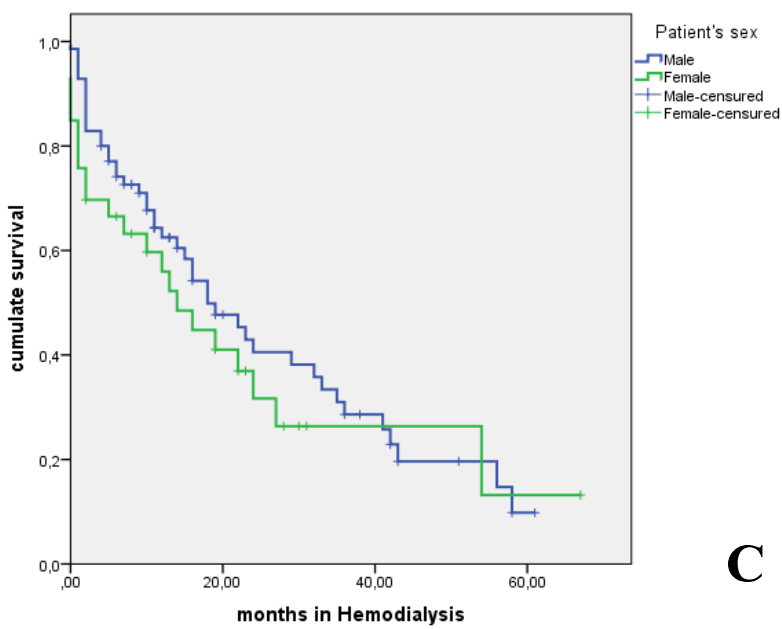

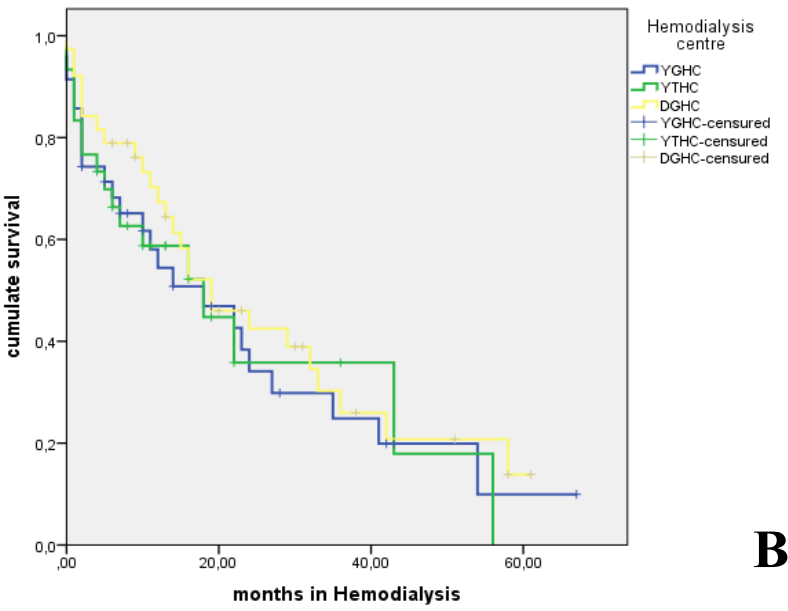

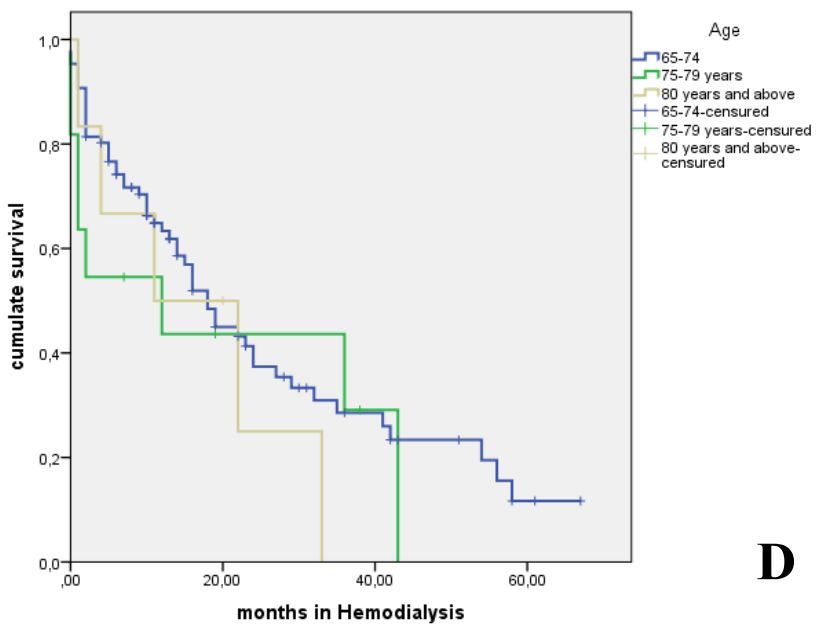

Figure 2: Elderly survival. (A) Overall survival. (B) Survival according to hemodialysis center. (C) Survival according to sex. (D) Survival according to age.

to those with low comorbidity index (33 months, $\mathrm{p}=0.016$ ) (Figure 3).

Emergency dialysis at initiation was also associated with low survival ( 14 months vs. 23 months $\mathrm{p}=0.04$ ). Mean survival of patients with high comorbidity index and emergency dialysis was 7 months compared to 54 months in high comorbidity and programmed dialysis $(\mathrm{p}=0.069)$. Patients with an arteriovenous fistula at dialysis initiation had a better survival compared to those without (median survival time: 27 months vs. 4 months, p<0.001) (Figure 4).

Absence of hospitalization was associated with a better survival (25 months vs. 11 month $\mathrm{p}=0.007$ ) (Figure 5). High comorbidity index hospitalized patients had a survival of 7 months compared to 24 months for the low comorbidity index non-hospitalized group $(p=0.022)$. Survival of patients with one hospitalization was similar to that of patients with several hospitalizations (10 months vs. 12 months, $\mathrm{p}=0.5$ ).

High comorbidity index (adjusted HR 2 [CI 1.125-3.57], p=0.018) and hospitalization (adjusted HR 2.12 [CI 1.198-3.77], $\mathrm{p}=0.010$ ) were both associated with low survival in multivariate analysis (Tables 4 and 5).

\section{Discussion}

\section{Baseline characteristics}

ESRD in Cameroon mainly affects young adults since more than $80 \%$ of incident chronic hemodialysis patients were aged between 20-64 years. However, from 2012 to 2017, the proportion of elderly patients who initiated hemodialysis raised from $1.6 \%$ to $12 \%$. A recent study in Cameroon reported that older patients represent up to $20 \%$ of the CKD patients [10] and the proportion of elderly needing dialysis may continue to increase.

Most of the older patients were male (68\%) and no female was found among very elderly patients ( $>80$ years). This could be explained by the fact that male gender is a CKD risk factor [13]. It could also reflect the local socio-cultural habits where older males are still considered as the pillar of the family and everything is done for their survival. Another reason could be that women seem to preferred conservative treatments as noted by previous studies $[8,14]$. Notably, in Austria, Reindl-Schwaighofer et al observed that elderly ESRD woman were more prevalent in conservative treatment compared to hemodialysis ( $95 \%$ vs. $5 \%$ ) [8]. 
Citation: Danielle FMEH, Francois KF, Diana TTH, Patrice HM, George TD, et al. (2019) Survival of Elderly Patients on Maintenance Hemodialysis: A 6 Years' Experience from a Resource-Limited Country. J Nephrol Ther 9: 331.
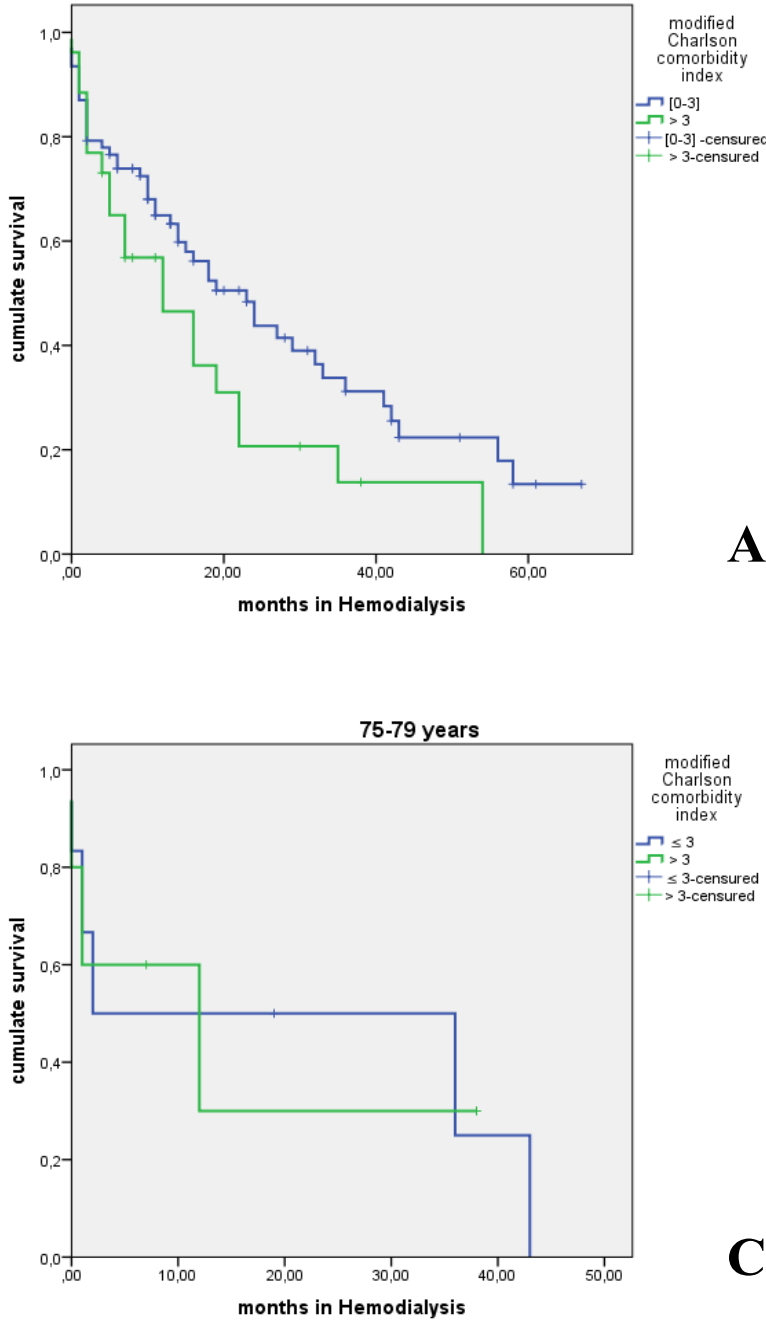

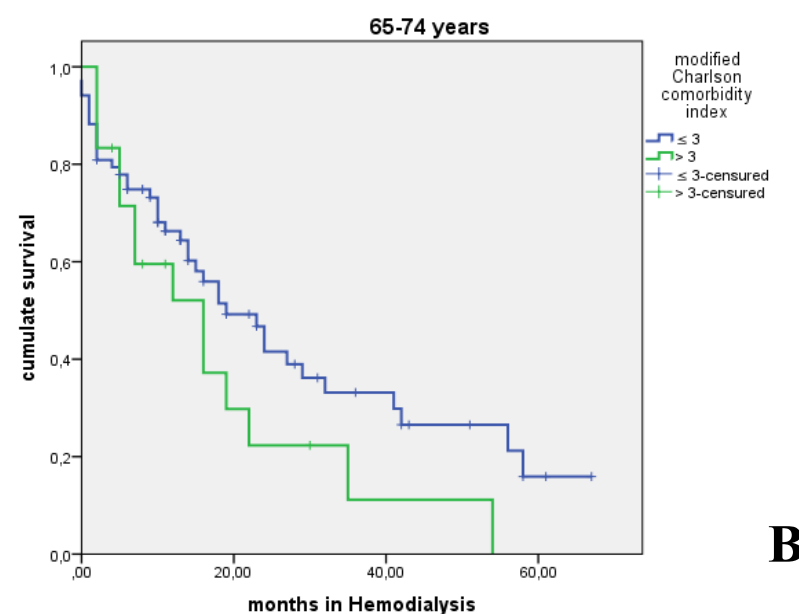

80 years and above

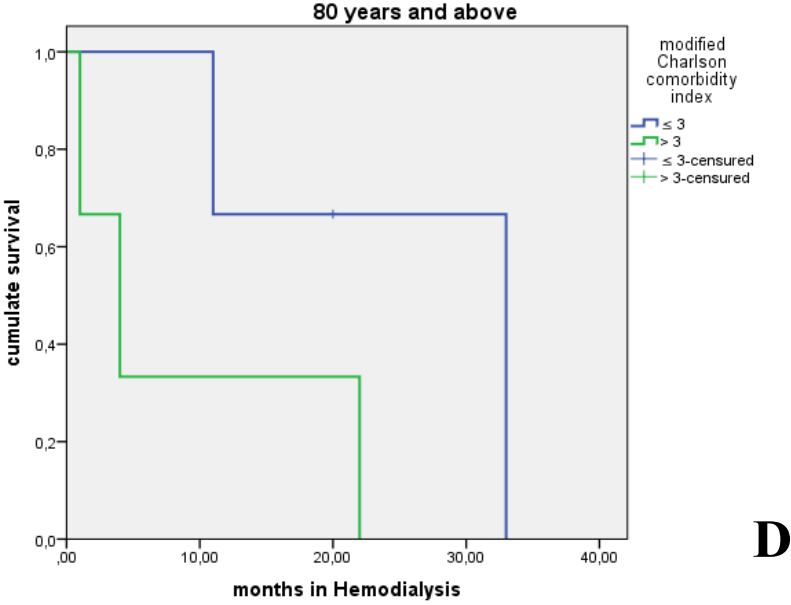

Figure 3: Elderly survival according to comorbidity. (A) Overall survival according to Charlson index. (B) Survival of patients 65-74 years according to comorbidities. (C) Survival of patients $75-80$ years according to comorbidities. (D) Survival of very elderly according to comorbidities.

\begin{tabular}{|c|c|c|}
\hline & Hazard ratio $(95 \% \mathrm{CI})$ & $\mathbf{p}$ \\
\hline \multicolumn{3}{|l|}{ Socio-demographic factors } \\
\hline Age $<70$ years & $0.9(0.5-1.4)$ & 0.54 \\
\hline Male & $0.8(0.5-1.3)$ & 0.4 \\
\hline single & $1.390 .7-2.2)$ & 0.36 \\
\hline Professional active & $1.1(0.7-1.9)$ & 0.66 \\
\hline \multicolumn{3}{|l|}{ Clinical factors } \\
\hline Pre-dialysis care $>3$ months & $0.9(0.5-1.8)$ & 0.8 \\
\hline Emergency dialysis & $2.2(1.2-3.9)$ & 0.013 \\
\hline Dialysis initiation on catheter & $2.1(1.1-4.2)$ & 0.032 \\
\hline Hospitalization & $2.1(1.2-3.5)$ & 0.007 \\
\hline Diabetes & $0.8(0.4-1.4)$ & 0.39 \\
\hline $\mathrm{mCCl} \leq 3$ & $0.5(0.3-0.9)$ & 0.013 \\
\hline Hemoglobin $>7 \mathrm{~g} / \mathrm{dl}$ & $0.9(0.6-1.8)$ & 0.98 \\
\hline
\end{tabular}

Table 4: Factors associated with low survival: univariate analysis.

They as in other reports, Hypertension, diabetes mellitus and cardiac failure were the main CKD comorbidities [14]. In our cohort, more than $90 \%$ of the participants had hypertension and more than
$70 \%$ had Diabetes Mellitus. However, most of our patients had low comorbidity since less than $25 \%$ had high comorbidity index. The proportion of malnutrition at dialysis initiation was also low in our 

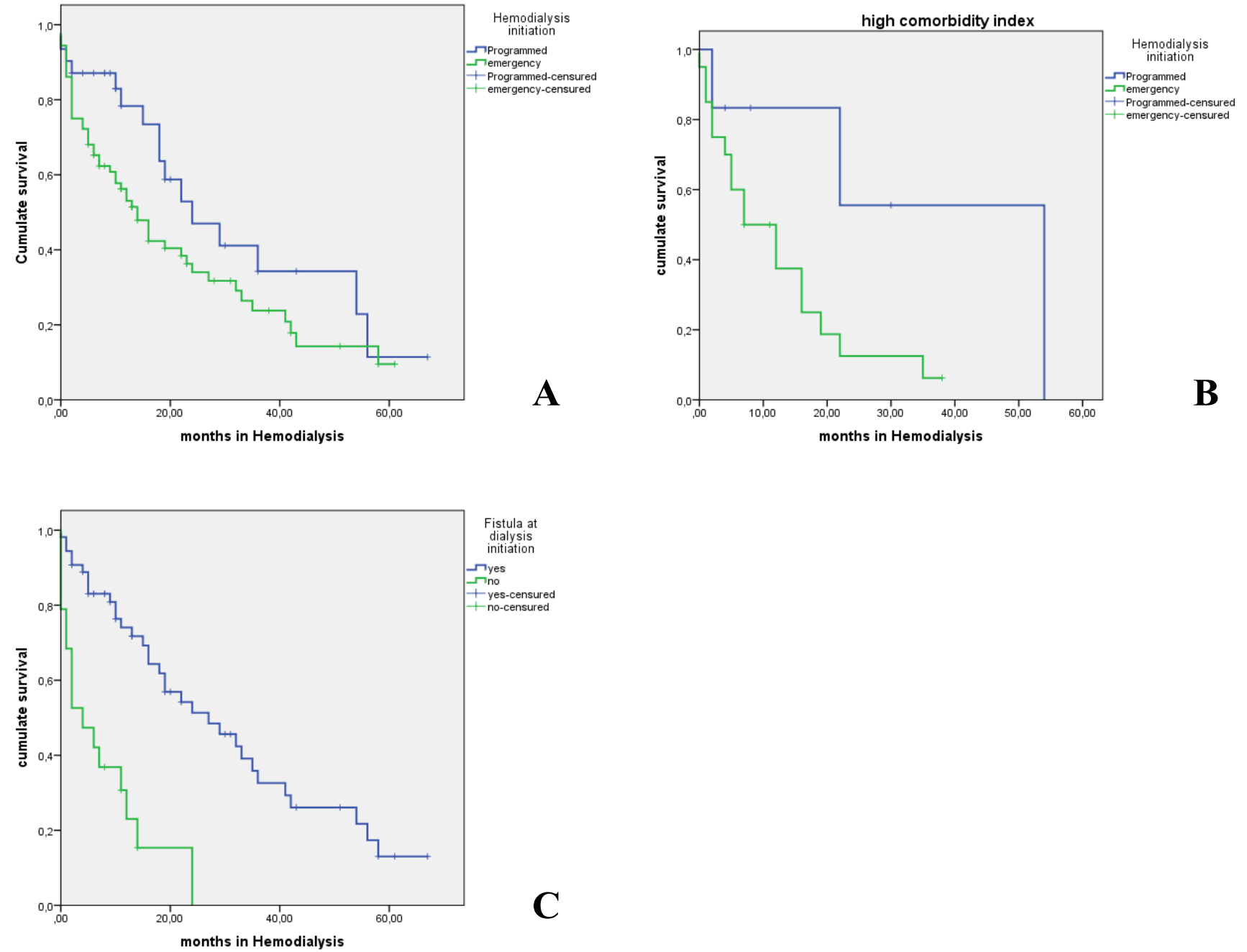

Figure 4: Elderly survival according to dialysis initiation. (A) Survival according to emergency/programmed dialysis initiation. (B) Survival among patients with high comorbidity index according to type of dialysis initiation. (C) Survival according to presence of fistula at dialysis initiation.

\begin{tabular}{|c|c|c|}
\hline & Ajusted HR (CI 95\%) \\
\hline Hospitalization & $2(1.125-3.57)$ \\
\hline Emergency dialysis initiation & $1.4(0.658-3.38)$ \\
\hline Dialysis initiation on catheter & $1.206(0.48-2.98)$ \\
\hline High comorbidity index & $2.12(1.198-3.770)$ \\
\hline
\end{tabular}

Table 5: Factors associated with low survival: multivariate analysis.

population. Thus, the survival time observed was largely independent from co-morbidities.

Pre-dialysis nephrology care was noted in $54.2 \%(\mathrm{n}=58)$ of our patients although less than a quarter had a fistula at dialysis initiation. Half of the patients who had a pre-dialysis $>12$ months started dialysis as emergency dialysis and without fistula. Halle et al. previous reported that emergency hemodialysis without a fistula is frequent among patients with pre-dialysis care (62.5\%) [15]. Since CKD as an indolent evolution, many patients are asymptomatic before ESRD and they do not understand the importance of programmed dialysis initiation.

\section{Mortality}

We found a mortality rate (59\%) similar to those reported in developed countries varying from $46-66 \%$ [14-18]. As known in adult populations, cardiovascular and infection remain the main causes of death described in older hemodialysis patients [14]. Unfortunately, the cause of death was available only for $30 \%$ of case because most of them happened at home. We assumed that dialysis redrawn and sudden death probably accounted for most of them.

We also found that hospitalization was associated with increase mortality. Hospitalization rate is known to be higher in elderly patient, however, in our setting, it may more reflect the hospitalized mortality. Moreover, since hemodialysis care is expensive, hospitalization usually concern very severe illness with high mortality risk such as catheter infection. 

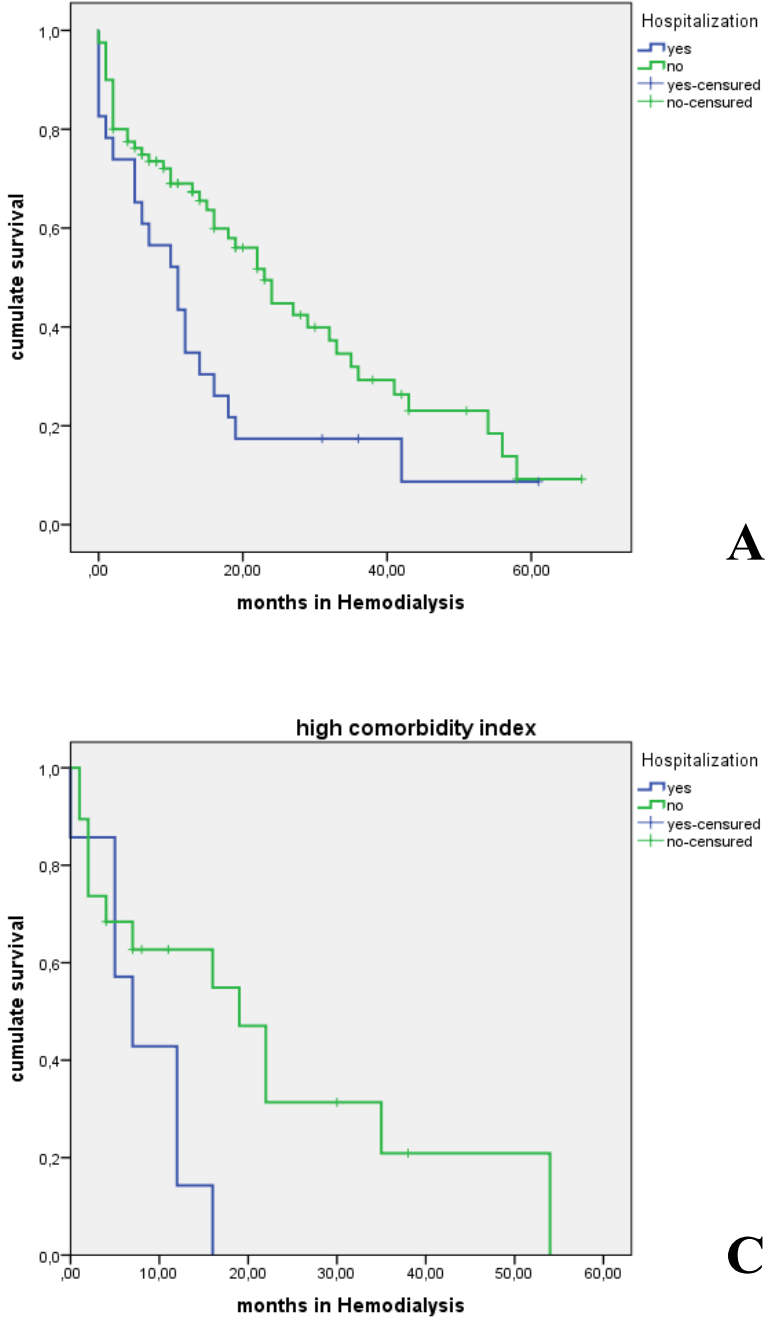

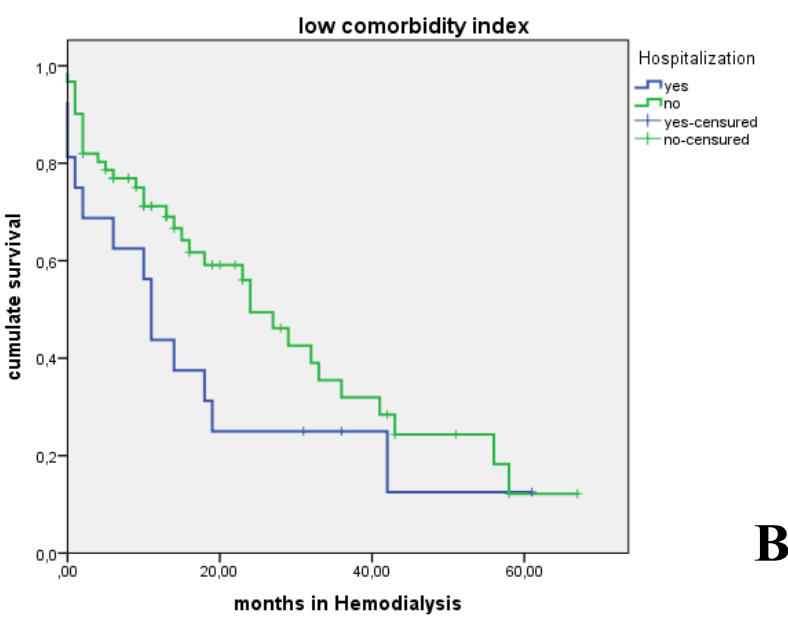

B

Figure 5: Elderly survival according to hospitalization. (A) Overall survival according to hospitalization. (B) Survival of patient with low comorbidity index according to hospitalization. (C) Survival of patient with high comorbidity index according to hospitalization.

\section{Survival}

Median survival time was 19 months and was comparable among sex, hemodialysis centers and age group. Kwok et al reported a median survival of 44.6 month in elderly dialysis patient in Hong Kong. However, Reindl-Schwaighofer et al, in Austria, and Jeloka et al, in India, respectively reported median survival of 26.9 month and 26.5 months $[8,19]$. Similar to our findings, Jeloka also reported that survival was comparable in elderly and very elderly patients [19].

As noted by many authors $[8,14,16,18,19]$, elderly patients with high comorbidity index had lower survival (13 months vs. 22 months, $\mathrm{p}=0.04$ ). As most of our patients had a low comorbidity index, it could explain our survival rate comparable to survival rate in India and Austria.

Emergency dialysis at initiation was associated with low survival, but after 5 years, survival rates were similar between emergency and programmed hemodialysis initiation. Older Cameroonian studies on dialysis survival also reported the importance of pre-dialysis care and programmed dialysis initiation [10]. More recently, Halle and al found that in adult hemodialysis patients, survival of patient with pre-dialysis compared to those without pre-dialysis care are better only during the first months but long term outcome of HD patients is more affected by initial comorbidity [15].

\section{Conclusion}

Incidence of elderly in chronic hemodialysis in Cameroon is increasing. Their survival time seems to be comparable to the survival time in some developed region. Comorbidity, programmed dialysis initiation and hospitalization are the main factor affecting survival in this population. Old age alone should not be an absolute contraindication of chronic hemodialysis initiation. A significant survival benefit could be observed in elderly as well as very elderly patients with low comorbidity and programmed dialysis initiation on an arteriovenous fistula.

\section{Study Limitations}

As a retrospective design, this study had many limitations. Twenty six patients (19.5\%) were excluded because of incomplete data. The data collected depended on the documentation of attending physician 
Citation: Danielle FMEH, Francois KF, Diana TTH, Patrice HM, George TD, et al. (2019) Survival of Elderly Patients on Maintenance Hemodialysis: A 6 Years' Experience from a Resource-Limited Country. J Nephrol Ther 9: 331.

during the follow up and some may be wrong, incomplete or biased. Some important information was also not available such as the mobility or mental status of elderly patients which could be important factors of survival. Evaluation of comorbidity was only clinical and some other comorbidity could have influence the outcome.

\section{Data availability}

The data used to support the finding of this study are available from the corresponding author upon request

\section{Conflicts of interest}

The authors declare that they have no conflicts of interest

\section{Funding statement}

The research was performed as the part of the employment of the authors at the Faculty of Medicine and Biomedical Sciences of Yaoundé-Cameroon.

\section{References}

1. Hill NR, Fatoba ST, Oke JL, Hirst JA, O'Callaghan CA, et al. (2016) Global Prevalence of Chronic Kidney Disease - A Systematic Review and MetaAnalysis. PloS one 11: e0158765.

2. Wang H, Naghavi M, Allen C, Barber RM, Bhutta ZA, et al. (2016) Global, regional, and national life expectancy, all-cause mortality, and cause-specific mortality for 249 causes of death, 1980-2015: a systematic analysis for the Global Burden of Disease Study 2015. Lancet 388:1459-1544.

3. Saran R, Robinson B, Abbott KC, Agodoa LYC, Bragg-Gresham J, et al (2018) United States Renal Data System 2018 USRDS annual data report Epidemiology of kidney disease in the United States. Am J Kidney Dis 73: A7-A8.

4. Pippias M, Stel VS, Diez JM, Afentakis N, Herrero-Calvos JA, et al. (2015) Renal replacement therapy in Europe: a summary of the 2012 ERA-EDTA registry Annual Report. Clin Kidney J 8: 248-61.

5. McClure M, Jorna T, Wilkinson L, Taylorl J (2017) Elderly patients with chronic kidney disease: do they really need referral to the nephrology clinic? Clinl Kidney J 10: 698-702.

6. Smith C, Da Silva-Gane M, Chandna S, Warwicker P, Greenwood R, et al.
(2003) Choosing not to dialyse: evaluation of planned non-dialytic management in a cohort of patients with end-stage renal failure. Nephron Clin Pract 95: c40-46.

7. Van Biesen W, Lameire N, Veys N, Vanderhaegen B (2004) From curing to caring: One character change makes a world of difference. Issues related to withholding/withdrawing renal replacement therapy (RRT) from patients with important co-morbidities. Nephrol Dial Transplant 19: 536-40.

8. Reindl-Schwaighofer R, Kainz A, Kammer M, Dumfarth A, Oberbauer R (2017) Survival analysis of conservative vs. dialysis treatment of elderly patients with CKD stage 5. PLoS One 12: e 0181345.

9. Ojo A (2014) Addressing the global burden of chronic kidney diease through clinical and translational research. Trans of Am Clin Climatol Assoc 125: 229-43.

10. Fouda H, Nono A, Kaze F, Halle MP, Mahamat M, et al. (2017) Epidemiology of chronic renal disease of the women at the Douala General Hospital. Health Sci Dis 18.

11. Fouda H, Ashuntantang G, Kaze F, Halle MP (2017) Survival among chronic hemodialysed patient in Cameroon. Pan Afr Med J 26: 97.

12. Hemmelgan BR, Manns BJ, Quan H, Ghali WA (2003) Adapting the Charlson comorbidity index for used in patient with ESRD. Am J Kidney Dis 42: 125-32.

13. Goldberg I, Krause I (2016) The role of gender in Chronic Kidney Disease. EMJ 1: 58-64.

14. Kwok WH, Yong SP, Kwok OL (2016) Outcomes in elderly patients with endstage renal disease: Comparison of renal replacement therapy and conservative management. Hong Kong Journal of Nephrology 19: 42-56.

15. Halle MP, Tsinga L, Fottsoh AF, Kaze FF, Sone AM, et al. (2017) Does Timing of Nephrology Referral Influence Outcome among Patients on Maintenance Hemodialysis in Cameroon? Health Sci Dis 18.

16. Tugcu M, Kasapoglu U, Sahin G, Apaydın S (2018) The Factors Affecting Survival in Geriatric Hemodialysis Patients. International Journal of Nephrology 2018: 4.

17. Klarić D, Pavlović PG, Klarić V (2016) Specificity of dialysis in the elderly dilemmas. Acta Med Croatica 70: 50-54.

18. Kan WC, Wang JJ, Wang SY, Sun YM, Hung CY, et al. (2013) The new comorbidity index for predicting survival in elderly dialysis patients: A long-term population-based study. PLoS One 8: e68748.

19. Jeloka T, Sanwaria P, Periera A, Pawar S (2016) Survival of elderly dialysis patients is not dependent on modality or "older" age. Indian J Nephrol 26: 23-26. 